\title{
The Association between Mycoplasma Species Infection and Tubal Obstruction
}

\author{
Hala Gomaa ${ }^{*}$, Eman Shaeer ${ }^{2}$, Samuel Soliman ${ }^{1}$ \\ ${ }^{1}$ New Life Fertility Center, Mississauga, Canada \\ ${ }^{2}$ Obstetrics and Gynaecology Department, Faculty of Medicine, Cairo University, Cairo, Egypt \\ Email: *halaobgyn99@yahoo.com
}

How to cite this paper: Gomaa, $\mathrm{H}$. Shaeer, E. and Soliman, S. (2018) The Association between Mycoplasma Species Infection and Tubal Obstruction. Open Journal of Obstetrics and Gynecology, 8, 1431-1437.

https://doi.org/10.4236/ojog.2018.813144

Received: October 27, 2018

Accepted: November 20, 2018

Published: November 23, 2018

Copyright $\odot 2018$ by authors and Scientific Research Publishing Inc. This work is licensed under the Creative Commons Attribution International License (CC BY 4.0).

http://creativecommons.org/licenses/by/4.0/

\begin{abstract}
Objectives: Numerous factors can cause infertility. Tubal factor accounts for approximately $30 \%$ of infertility in females. This study was conducted to evaluate the rate of asymptomatic Mycoplasma hominis and Ureaplasma urealyticum infection in females diagnosed with tubal obstruction. Methods: This is a retrospective case-control study conducted at New Life Fertility Centre. We have identified and reviewed the health records of 167 subfertile women that had HSG and an endocervical swab for Mycoplasma hominis and Ureaplasma urealyticum done. Results: We compared the endocervical swab results of ureaplasma and mycoplasma in the patients with tubal obstruction (group 1) to the patients with normal patent tubes (group 2). Diagnosis of tubal patency was based on the HSG results. Our results show that there is a significantly higher rate of Ureaplasma urealyticum/Mycoplasma hominis infection in group 1 compared to group 2. Conclusion: Our data shows that there is a high rate of $U$. urealyticum and $M$. hominis infection in patients diagnosed with tubal factor of infertility and it can be a marker in the prediction of the tubal pathology.
\end{abstract}

\section{Keywords}

Infertility, Tubal Factor, Hysterosalpingogram, Ureaplasma urealyticum, Mycoplasma hominis

\section{Introduction}

Infertility is an important subject of reproductive health with a prevalence of $12.5 \%$ among women [1]. It has an impact on the quality of life for these patients [2]. Many studies discussed the relationship between infection and tubal factor of infertility [3]. 
Since Ureaplasma was identified as a cause of male urethritis in 1954 [4], it is considered as the most common cause of genital infection in both males and females [5] [6]. Both Ureaplasma and Mycoplasma are found in genitourinary samples [6].

Ureaplasma has 14 known serotypes [7]. U. urealyticum is considered to be the pathogenic organism [8].

Also, it was found that it may be related to unexplained infertility [9].

Not too much is known about its prevalence in pelvic inflammatory disease (PID) [10].

Tubal factor assessment is fundamental in a fertility workup. Many interventions can be used for tubal pathology evaluation [11]. However, Hysterosalpingogram (HSG) has a high sensitivity and specificity for diagnosis of tubal obstruction [12] and is widely used.

The aim of this study is to find out if there is a relationship between endocervical Mycoplasma, Ureaplasma infection and tubal factor of infertility.

Key Points:

The investigation was to see the correlation between genital mycoplas$\mathrm{ma} /$ ureaplasma infection and tubal obstruction in sub-fertile women.

\section{Materials and Methods}

This is a retrospective case-control study conducted at New Life Fertility Centre and Brampton Civic Hospital in Brampton, ON, Canada, in which 167 infertile females who had HSG and an endocervical swab for Mycoplasma hominis and Ureaplasma urealyticum done.

In between May 2015 to December 2017 were included. The study was approved by the Research Ethics Committee of the Brampton Civic Hospital. Approval number 17-0040.

An endocervical swab was obtained from all of the patients as part of the investigative cycle. Swabs were then immediately placed into a collection tube containing UTM-RT media (Ureaplasma and Mycoplasma spp.) (Copan ITALIA). All of the samples are stored at $4^{\circ} \mathrm{C}$ and then transported to the laboratory (Gamma dynacare, Canada) within $24 \mathrm{~h}$ of collection. The samples were cultured using A8 Mycoplasma Agar.

All of the candidates had HSG done in the luteal phase in Brampton Civic Hospital; Brampton, ON, Canada. We collected and analyzed the clinical data, including demographic information, HSG reports and endocervical swab results. The patients included in the study did not have a previous medical history of PID, chlamydia infection or any other risk factors that increase the risk of tubal disease such as: pelvic/abdominal surgery, previous ectopic pregnancy or a history of endometriosis. Other exclusion criteria included current use of antibiotics. The outcome was the rate of $U$. ureaplasmal $M$. hominis infection in patients with tubal obstruction either unilateral or bilateral compared to the rate of infection in patients with open tubes. 


\section{Patient and Public Involvement}

Since this is a retrospective study, patients were not directly involved. The data was collected from medical records of patients that were already being treated at the clinic with their consent. As a routine, we do cervical swab to test Mycoplasma/Ureaplasma infection. It was noted that most of the patients that had the infection also had tubal obstruction in the HSG. The results were dispersed to study participants by excluding any patient who already had or was at risk of having tubal disease. That ensured accuracy.

\section{Statistical Analysis}

Data were collected and analyzed using Microsoft Excel version 7. Data was described in terms of mean and SD. Outcomes were compared using student $t$ test. Statistical software was used for data analysis. P-values $<0.05$ were considered statistically significant.

\section{Results}

A total of 167 patients; either primary or secondary infertility (Table 1).

We compared the endocervical swab results of:

Group 1: The patients with tubal obstruction (81 patients) (41 patients with unilateral tubal obstruction and 40 patients with bilateral tubal obstruction) to Group 2: The patients with normal patent tubes (86 patient) (Table 2). Diagnosis of tubal patency was based on HSG results. Our results show that there is a significantly higher rate of infection in group 1 than in group 2, $(64.19 \%$ vs $12.79 \%$, P value $<0.0001$ ) (Table 2).

Rate of $U$. urealyticum infection in group 1: $49.38 \%$.

Rate of $M$. hominis infection in group 1: 8.64\%.

Rate of mixed $U$. urealyticum and $M$. hominis co-infection in group 1: 6.17\%.

Rate of $U$. urealyticum infection in group 2: $12.79 \%$.

Table 1. Patients' age and type of infertility.

\begin{tabular}{ccc}
\hline & Group 1 & Group 2 \\
\hline Age & $38.0 \pm 5.04$ & $35.4 \pm 4.83$ \\
1ry Infertility & 25 & 36 \\
2ry Infertility & 56 & 50 \\
\hline
\end{tabular}

Table 2. Rate of $U$. ureaplasma/M. hominis infection in both groups.

\begin{tabular}{cccc}
\hline Endo-cervical swab result & $\begin{array}{c}\text { Group 1 } \\
\text { [81 patients] }\end{array}$ & $\begin{array}{c}\text { Group 2 } \\
\text { [86 patients] }\end{array}$ & P value \\
\hline +ve U. urealyticum & $40 / 81[49.39 \%]$ & $11 / 86[12.79 \%]$ & $<0.0001$ \\
+ve M. hominis & $7 / 81[8.64 \%]$ & $0 / 86$ & 0.005 \\
Mixed infection & $5 / 81[6.17 \%]$ & $0 / 86$ & 0.025 \\
Total no of infected patients & $52 / 81[64.19 \%]$ & $11 / 86[12.79 \%]$ & $<0.0001$ \\
\hline
\end{tabular}


Rate of $M$. hominis in group 2: $0 \%$.

Rate of mixed $U$. urealyticum and $M$. hominis co-infection in group 2: $0 \%$.

Odd Ratio: 12.22 .

\section{Discussion}

Although Neisseria gonorrhoea and chlamydia are the most common causative organisms for PID, still 70\% of cases are of unknown causes [13]. Little data is available regarding the involvement of other organisms within the vaginal micro-environment in the development of PID and tubal pathology [14]. Several studies have described genital Mycoplasma and Ureaplasma as causative agents of PID [15].

A8 Mycoplasma Agar is a sensitive method for detection of genital mycoplasma [16].

In the current study, the rate of Mycoplasma hominis and Ureaplasma urealyticum genital infections in a group of asymptomatic women was significantly higher in females diagnosed with tubal obstruction compared to those with patent tubes $(64.19 \%$ vs $12.79 \%, \mathrm{P}<0.0001)$. The percentage of Ureaplasma infection was higher than Mycoplasma in the tubal obstruction group (49.38\% vs. 8.64\%) and $12.79 \%$ for Ureaplasma with no Mycoplasma recorded in the healthy group.

Mycoplasma is a common cause of cervicitis that may be complicated by ascending infection involving the uterine cavity, tubes and ovaries with the subsequent development of PID [17].

Tubal factor accounts for approximately $30 \%$ - 35\% of cases of female infertility and is a major sequel of PID [18].

In a large study from the Netherlands on 1188 patients screened for STDs, Mycoplasma was the second most common organism detected (4.5\%) after chlamydia (8.3\%) [19]. In vitro studies on mice have detected Mycoplasma in the genital tract causing structural changes in the ciliated epithelium of the fallopian tubes [20]. Mycoplasma has also been found to be a cause of salpingitis in monkeys [21]. In PEACH study (PID Evaluation and Clinical Health study), Haggerty et al. reported a trend towards an increase in the rate of infertility and PID as well as drop in pregnancy and live birth rates in those suffering from Mycoplasma genitalium [22]. In another study on 212 infertile couples, an independent association between Mycoplasma genitalium and tubal factor infertility has been reported [23]. Tubal occlusion was found in 33\% of Mycoplasma positive infertile females in a prospective study on 200 Indian women [24]. Clausen et al. detected Mycoplasma genitalium in 22\% of females suffering from tubal factor infertility compared to $6.3 \%$ without tubal pathology [25].

On the contrary, IDahl et al. reported insignificant association between Mycoplasma genitalium serum IgG and female infertility after adjusting to chlamydia trachomatis IgG. This association was not found with subtypes of infertility; however, in this study tubal factor was not excluded by laparoscopy or hystero- 
salpingography in some of the studied women [26]. In another Brazilian study, Costaya et al. did not detect Mycoplasma species in the fallopian tubes of females with tubo-peritoneal infertility and the organism was only detected in samples free from other organisms. Infertility could not be excluded in this study due to the low number of infected cases [27].

In a current study, the cohort of patients selected was asymptomatic for genital infection and did not give a history suggestive of PID or other risk factors for tubal pathology. Unlike Neisseria gonorrhoea, genital Mycoplasma and chlamydia have less overt inflammatory manifestations [28] and many of those infected with Mycoplasma are asymptomatic carriers resulting in delayed diagnosis and treatment with subsequent deleterious effects on fertility [29] [30]. In addition, Mycoplasma has a high drug resistance to medications commonly used for treatment of PID causing treatment failure and persistent PID eventuates [22].

\section{Conclusion}

In conclusion, Mycoplasma is an overlooked genital infection that is mostly asymptomatic with high reproductive morbidity. This highlights the importance of including Mycoplasma genitalium in screening programs for STDs and those at high risk for PID.

\section{Limitations}

One of the limitations of this study, that we used a retrospective data which didn't include the most recent screening for chlamydia or gonorrhea infection.

Further studies are needed to include screening for $U$. urealyticum and $M$. hominis and other genital infection at the same time, to identify the best screening methods and treatment options for the organism.

\section{Conflicts of Interest}

The authors declare that they have no conflict of interest.

\section{References}

[1] Datta, J., Palmer, M.J., Tanton, C., Gibson, L.J., Jones, K.G., Macdowall, W., et al. (2016) Prevalence of Infertility and Help Seeking among 15000 Women and Men. Human Reproduction, 31, 2108-2118. https://doi.org/10.1093/humrep/dew123

[2] Chachamovich, J.R., Chachamovich, E., Ezer, H., Fleck, M.P., Knauth, D. and Passos, E.P. (2010) Investigating Quality of Life and Health-Related Quality of Life in Infertility: A Systematic Review. Journal of Psychosomatic Obstetrics and Gynaecology, 31, 101-110. https://doi.org/10.3109/0167482X.2010.481337

[3] Cates, W., Rolfs, R.T. and Aral, S.O. (1990) Sexually Transmitted Diseases, Pelvic Inflammatory Disease, and Infertility: An Epidemiologic Update. Epidemiologic Reviews, 12, 199-220. https://doi.org/10.1093/oxfordjournals.epirev.a036054

[4] Shepard, M.C. (1954) The Recovery of Pleuropneumonia-Like Organisms from Negro Men with and without Nongonococcal Urethritis. American Journal of Syphilis, Gonorrhea, and Venereal Diseases, 38, 113-24. 
[5] Waites, K.B., Katz, B. and Schelonka, R.L. (2005) Mycoplasmas and Ureaplasmas as Neonatal Pathogens. Clinical Microbiology Reviews, 18, 757-789. https://doi.org/10.1128/CMR.18.4.757-789.2005

[6] Taylor-Robinson, D. (1996) Infections Due to Species of Mycoplasma and Ureaplasma: An Update. Clinical Infectious Diseases, 23, 671-682. https://doi.org/10.1093/clinids/23.4.671

[7] Kokkayil, P. and Dhawan, B. (2015) Ureaplasma: Current Perspectives. Indian Journal of Medical Microbiology, 33, 205-214. https://doi.org/10.4103/0255-0857.154850

[8] Xiao, L., Paralanov, V., Glass, J.I., Duffy, L.B., Robertson, J.A., Cassell, G.H., et al. (2011) Extensive Horizontal Gene Transfer in Ureaplasmas from Humans Questions the Utility of Serotyping for Diagnostic Purposes. Journal of Clinical Microbiology, 49, 2818-2826. https://doi.org/10.1128/JCM.00637-11

[9] Gupta, A., Gupta, S., Mittal, A., Chandra, P. and Gill, A.K. (2009) Correlation of Mycoplasma with Unexplained Infertility. Archives of Gynecology and Obstetrics, 280, 981-985. https://doi.org/10.1007/s00404-009-1042-z

[10] Simms, I., Eastick, K., Mallinson, H., Thomas, K., Gokhale, R., Hay, P., et al. (2003) Associations between Mycoplasma genitalium, Chlamydia trachomatis, and Pelvic Inflammatory Disease. Sexually Transmitted Infections, 79, 154-156. https://doi.org/10.1136/sti.79.2.154

[11] Panchal, S. and Nagori, C. (2014) Imaging Techniques for Assessment of Tubal Status. Journal of Human Reproductive Sciences, 7, 2-12.

https://doi.org/10.4103/0974-1208.130797

[12] Lim, C.P., Hasafa, Z., Bhattacharya, S. and Maheshwari, A. (2011) Should A Hysterosalpingogram Be a First-Line Investigation to Diagnose Female Tubal Subfertility in the Modern Subfertility Workup? Human Reproduction, 26, 967-971. https://doi.org/10.1093/humrep/der046

[13] Quentin, R. and Verdon, R. (2012) Microbiologic Basis of Diagnosis and Treatment of Pelvic Inflammatory Disease. Journal de Gynécologie Obstétrique et Biologie de la Reproduction (Paris), 41, 850-863. https://doi.org/10.1016/j.jgyn.2012.09.015

[14] Tsevat, D.G., Wiesenfeld, H.C., Parks, C. and Peipert, J.F. (2017) Sexually Transmitted Diseases and Infertility. American Journal of Obstetrics \& Gynecology, 216, 1-9. https://doi.org/10.1016/j.ajog.2016.08.008

[15] Manhart, L.E. (2013) Mycoplasma genitalium: An Emergent Sexually Transmitted Disease? Infectious Disease Clinics of North America, 27, 779-792. https://doi.org/10.1016/j.idc.2013.08.003

[16] Broitman, N.L., Floyd, C.M., Johnson, C.A., de la Maza, L.M. and Peterson, E.M. (1992) Comparison of Commercially Available Media for Detection and Isolation of Ureaplasma urealyticum and Mycoplasma hominis. Journal of Clinical Microbiology, 30, 1335-1337.

[17] Falk, L., Fredlund, H. and Jensen, J.S. (2005) Signs and Symptoms of Urethritis and Cervicitis among Women with or without Mycoplasma genitalium or Chlamydia trachomatis Infection. Sexually Transmitted Infections, 81, 73-78. https://doi.org/10.1136/sti.2004.010439

[18] Lindsay, T.J. and Vitrikas, K.R. (2015) Evaluation and Treatment of Infertility. American Family Physician, 91, 308-314.

[19] De Jong, A.S., Rahamat-Langendoen, J.C., van Alphen, P., Hilt, N., van Herk, C., Pont, S., et al. (2016) Large Two-Centre Study into the Prevalence of Mycoplasma genitalium and Trichomonas vaginalis in the Netherlands. International Journal of 
STD \& AIDS, 27, 856-860. https://doi.org/10.1177/0956462415596496

[20] Baczynska, A., Funch, P., Fedder, J., Knudsen, H.J., Birkelund, S. and Christiansen, G. (2007) Morphology of Human Fallopian Tubes after Infection with Mycoplasma genitalium and Mycoplasma hominis - in Vitro Organ Culture Study. Human Reproduction, 22, 968-979. https://doi.org/10.1093/humrep/del455

[21] Møller, B.R., Taylor-Robinson, D., Furr, P.M. and Freundt, E.A. (1985) Acute Upper Genital-Tract Disease in Female Monkeys Provoked Experimentally by Mycoplasma genitalium. British Journal of Experimental Pathology, 66, 417-426.

[22] Haggerty, C.L., Totten, P.A., Astete, S.G., Lee, S., Hoferka, S.L., Kelsey, S.F., et al. (2008) Failure of Cefoxitin and Doxycycline to Eradicate Endometrial Mycoplasma genitalium and the Consequence for Clinical Cure of Pelvic Inflammatory Disease. Sexually Transmitted Infections, 84, 338-342. https://doi.org/10.1136/sti.2008.030486

[23] Svenstrup, H.F., Fedder, J., Kristoffersen, S.E., Trolle, B., Birkelund, S. and Christiansen, G. (2008) Mycoplasma genitalium, Chlamydia trachomatis, and Tubal Factor Infertility-A Prospective Study. Fertility and Sterility, 90, 513-520. https://doi.org/10.1016/j.fertnstert.2006.12.056

[24] Rajkumari, N., Kaur, H., Roy, A., Gupta, N., Dhaliwal, L.K. and Sethi, S. (2015) Association of Mycoplasma genitalium with Infertility in North Indian Women. Indian Journal of Sexually Transmitted Diseases and AIDS, 36, 144-148. https://doi.org/10.4103/0253-7184.167141

[25] Clausen, H.F., Fedder, J., Drasbek, M., Nielsen, P.K., Toft, B., Ingerslev, H.J., et al. (2001) Serological Investigation of Mycoplasma genitalium in Infertile Women. Human Reproduction, 16, 1866-1874. https://doi.org/10.1093/humrep/16.9.1866

[26] Idahl, A., Jurstrand, M., Olofsson, J.I. and Fredlund, H. (2015) Mycoplasma genitalium Serum Antibodies in Infertile Couples and Fertile Women. Sexually Transmitted Infections, 91, 589-591. https://doi.org/10.1136/sextrans-2015-052011

[27] Costoya, A., Morales, F., Borda, P., Vargas, R., Fuhrer, J., Salgado, N., et al. (2012) Mycoplasmateceae Species Are Not Found in Fallopian Tubes of Women with Tubo-Peritoneal Infertility. The Brazilian Journal of Infectious Diseases, 16, 273-278. https://doi.org/10.1016/S1413-8670(12)70323-9

[28] Short, V.L., Totten, P.A., Ness, R.B., Astete, S.G., Kelsey, S.F. and Haggerty, C.L. (2009) Clinical Presentation of Mycoplasma genitalium Infection versus Neisseria Gonorrhoeae Infection among Women with Pelvic Inflammatory Disease. Clinical Infectious Diseases, 48, 41-47. https://doi.org/10.1086/594123

[29] Thurman, A.R., Musatovova, O., Perdue, S., Shain, R.N., Baseman, J.G. and Baseman, J.B. (2010) Mycoplasma genitalium Symptoms, Concordance and Treatment in High-Risk Sexual Dyads. International Journal of STD \& AIDS, 21, 177-183. https://doi.org/10.1258/ijsa.2009.008485

[30] Haggerty, C.L. and Taylor, B.D. (2011) Mycoplasma genitalium: An Emerging Cause of Pelvic Inflammatory Disease. Infectious Diseases in Obstetrics and Gynecology, 2011, Article ID: 959816. 